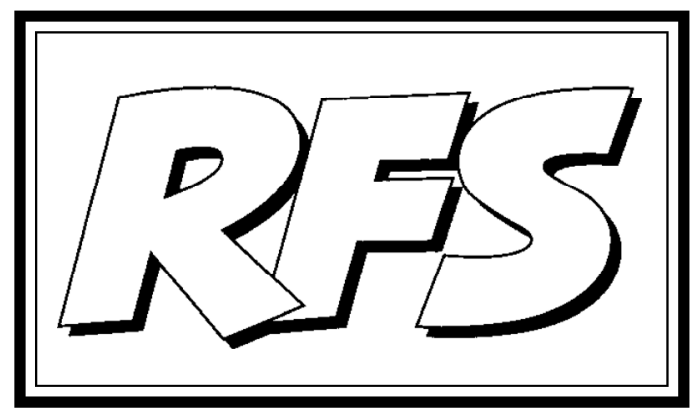

Revista de Fomento Social, 53 (1998), 3-29

\title{
La batalla del aceite... y otras batallas
}

\section{Consejo de Redacción}

\section{Introducción: la alarma salta}

Desde mediados del año pasado (1997) y sobre todo a partir del mes de diciembre, el debate sobre la reforma de la Organización Común de Mercado (en adelante OCM) del aceite de oliva (que así se llama la reglamentación comunitaria correspondiente) ha saltado a la actualidad nacional. Prescindiendo de acontecimientos menos importantes o anecdóticos, los hechos principales se han sucedido - hasta la fecha de redacción del presente texto- según el siguiente «calendario»:

- Durante el año 1996 la Comisión presentó un borrador de nueva OCM.

- 23 de octubre de 1996: el Consejo Económico y Social emite un informe sobre la OCM.

- 12 de febrero de 1997: tras numerosas modificaciones se aprobó por 
el Consejo de Comisarios un documento de reflexión, al que nos referiremos más adelante.

- 18 de diciembre de 1997: el Parlamento Europeo aprueba el «dictamen Jové» por una amplia mayoría; de alguna manera España gana la batalla del aceite en el Parlamento Europeo, aunque dicho dictamen carece de poder vinculante.

- Diciembre 97: se «filtra» un borrador de reforma del Comisario Fischler.

- 19 de febrero de 1998: el Comisario Fischler anuncia en Estrasburgo su intención de incorporar a su propuesta algunas de las tesis defendidas por España, en particular manteniendo las ayudas a la producción, al menos durante un periodo transitorio. Reacción prudente de los gobiernos y sectores implicados.

- 27 de febrero de 1997: masivas movilizaciones unitarias contra la llamada «reforma Fischler», convocadas por la Mesa Nacional del Aceite, especialmente concurridas en las ciudades de Jaén y Córdoba.

- 18 de marzo de 1998: propuesta definitiva de la Comisión. A la fecha de cierre del presente texto, está pendiente de votación -por mayoría cualificada: no hay derecho de veto- en el Consejo de Ministros.

En efecto, el día 18 de marzo de 1998 el Colegio de Comisarios, o sea, la Comisión Europea, a propuesta del Comisario de agricultura Franz Fischler, presentó oficialmente su propuesta de reforma de la OCM del Aceite de Oliva en el marco de un conjunto mucho más amplio de propuestas legislativas. Este importante «paquete» [Documento de la Comisión IP/98/258] incluye: a) una serie de reglamentos agrarios; b) reglamentos relativos a los Fondos estructurales y de Cohesión; c) instrumentos preadhesión, relativos a la ampliación hacia los países del Este; $y$ d) perspectivas financieras para el periodo 2000-2006, lo que constituye el marco presupuestario plurianual de la UE.

La situación coyuntural del subsector del olivar y el aceite, en la que se ha elaborado este artículo editorial, es ampliamente conocida por casi todos los españoles y con mayor profundidad por los andaluces en general y los agricultores olivareros en particular. Se podría decir que la «batalla» que se libra en contra de la propuesta de reforma de la OCM para las materias grasas, elaborada por la Comisión europea de agricultura, ha 
sido difundida por todas las partes implicadas en nuestro país -agricultores, administraciones públicas, etc.- como una afrenta a los intereses nacionales. Desde luego, hay que reconocer que la propuesta de reforma supone un cambio cualitativo y cuantitativo que, de llevarse a cabo, modificará profundamente la estructura productiva y la capacidad de generación de renta de este importante subsector.

Un debate tan extendido, tan apasionado, y tan divulgado como el que nos ocupa, no puede ser abordado sin antes caer en la cuenta de que al afrontarlo se encuentran en juego dos racionalidades radicalmente diferentes e incluso contradictorias: por un lado la racionalidad económica, que nos atrevemos de calificar de "objetiva», y por otro la "racionalidad» política, los intereses electorales ajenos a la racionalidad económica y los intereses corporativos segmentados, pese a la apariencia (falsa) de homogeneidad. Ello da lugar a notables contradicciones en todo el proceso. La negociación de este importante tema, en particular, tiene unos caracteres muy peculiares: por un lado están en juego decisiones de alcance estratégico, porque estarán vigentes en un plazo relativamente largo y tendrán consecuencias muy extendidas; por otro lado, los aspectos tácticos, sometidos al coyunturalismo más elemental, y orientados a ampliar lo que podríamos llamar «la zona de regateo» de la negociación propiamente dicha, adquieren una gran relevancia, sobre todo cuando todo el proceso se convierte también en un suceso «mediático» sometido a la censura o aprobación social masiva.

Con este artículo editorial, pretendemos arrojar algo de luz en este gigantesco «saco de ambigüedades»: una pretensión probablemente desmedida. Al lector le corresponde la tarea de juzgar...

\section{Situación previa a la reforma Fischler: producción de aceite y sistema de subvenciones}

La importancia del olivar, especialmente en Andalucía

La importancia del olivar, y la de su producto por excelencia el aceite de oliva, se ha traducido incluso en su significación cultural y lingüistica que ha reservado para el de oliva el término de aceite por antonomasia. En 
efecto, según el diccionario de la Real Academia Española, se entiende por aceite, en su primera acepción, la "grasa líquida de color verde amarillento que se obtiene por presión de las aceitunas», por tanto, se puede deducir que el resto de aceites vegetales lo son "por extensión»; digamos que son "pseudoaceites»...; propiamente deberíamos hablar de grasas, frente al aceite por antonomasia, el de oliva.

Consideraciones lingüísticas aparte, el olivar ocupa más de 2,2 millones de hectáreas de superficie agrícola en España, la casi totalidad dedicadas a la producción de aceituna de almazara, ya que sólo unas 200.000 hectáreas se dedican a la producción de aceituna de mesa.

En cuanto a la producción de aceite, en el cuadro siguiente aparece en miles de toneladas. La variación se debe por un lado a la tradicional «vecería» de este cultivo, pero también a la presencia de años de sequía en épocas más recientes. La serie histórica de producciones por campaña (no por años naturales) que aparece a continuación tiene una enorme importancia estratégica; de sus diferentes interpretaciones depende cuál sea la Cantidad Máxima Garantizada (en adelante, CMG) que se consiga para España. Obsérvese que la media del periodo es de 598.930 toneladas.

\begin{tabular}{|c|c|c|c|}
\hline Campaña & $\begin{array}{c}\text { Producción } \\
\text { (miles de Tm) }\end{array}$ & Campaña & $\begin{array}{c}\text { Producción } \\
\text { (miles de Tm) }\end{array}$ \\
\hline $1988 / 1989$ & 399,4 & $1993 / 1994$ & 542,0 \\
$1989 / 1990$ & 550,8 & $1994 / 1995$ & 462,4 \\
$1990 / 1991$ & 639,4 & $1995 / 1996$ & 356,0 \\
$1991 / 1992$ & 592,9 & $1996 / 1997$ & 947,4 \\
$1992 / 1993$ & 623,0 & $1997 / 1998$ & 869,0 (rovisional) \\
\hline
\end{tabular}

Hablar del olivo y de su producto por excelencia, el aceite de oliva, es hacer referencia de forma obligada a la agricultura andaluza. Andalucía es la primera región o zona geográfica en superficie dedicada a la producción de aceitunas en general y de aceitunas para la fabricación de aceite en particular. El aceite de oliva representa para Andalucía entre el $15 \%$ y el $20 \%$ de la producción final agraria y en ella se produce más del $75 \%$ del aceite de oliva española, el 36\% del comunitario y el 27\% del mundial. Por su parte, el olivar, sobre todo por la recogida de la aceituna 
en España, genera una cifra media en torno a los 45 millones de jornales, muy concentrados en los meses de invierno.

El sector agrario español en su conjunto recibe, en concepto de subvenciones agrarias relativas a precios y mercados, cerca de un billón de pesetas del FEOGA. De esas ayudas agrarias, más de la cuarta parte corresponden a Andalucía; representando las ayudas al aceite en sus diversas modalidades en torno a 100.000 millones de pesetas, más del 40\% del total de subvenciones agrarias recibidas en Andalucía y aproximadamente el 12,5\% de las nacionales. Para tener un orden de comparación, el presupuesto de la Junta de Andalucía asciende a algo más de 2 billones de pesetas.

Descendiendo a escala de explotación agraria, los estudios realizados en ETEA permiten afirmar que -según la dimensión de la finca- las subvenciones de las explotaciones de secano productoras de cereales, de oleaginosas, y de olivar, representan entre el 15 y el 25\% del total de su cifra de ventas; ahora bien, sobre el margen neto o beneficio del agricultor, dicho porcentaje asciende a una cifra muy significativa, que oscila-según los casos-entre el 30\% y el 60\%. El número de agricultores andaluces perceptores de subvención puede superar los 150.000, a juzgar por el número de solicitudes de subvención presentadas en la última campaña.

Una producción altamente subvencionada

Desde el comienzo de la Política Agraria de la Comunidad Europea (en adelante, PAC), y gracias a la presencia italiana en los orígenes de la misma (Conferencia de Stressa), el aceite de oliva cuenta con un elevado grado de protección, similar, por otro lado, al de los cereales. Para comprender los términos de la «batalla» del aceite es preciso explicar aunque sea de forma resumida- cuáles son los mecanismos protectores vigentes desde hace décadas en la UE y cuáles las modificaciones propuestas. El aceite de oliva ha contado con un precio de garantía y un fuerte aislamiento del mercado mundial.

Las medidas de intervención giran alrededor de un sistema de compras en régimen de garantía a un determinado precio y de un régimen de ayudas 
que tiende a favorecer en mayor medida a los productores que a los consumidores. Para no entrar en excesivos detalles, prescindimos de la explicación de los diferentes precios existentes (precio indicativo, precio representativo de mercado, precio umbral o de entrada y precio de intervención o de garantía).

La UE destina unos 2.000 millones de ecus -unos 330.000 millones de pesetas- en concepto de ayudas al sector olivarero. A pesar de la importancia de esa cifra, estas ayudas al aceite sólo representan alrededor del 5\% del total de gastos agrarios comunitarios. Son los productos llamados continentales (cereales, oleaginosas y proteaginosas y productos ganaderos) los que se llevan «la parte del león» de las ayudas agrarias: en torno al $80 \%$ del total. No conviene, sin embargo olvidar, que también en regiones olivareras como Andalucía, son las subvenciones a productos como los cereales y el girasol las que ocupan el primer lugar en volumen financiero, por delante de las del aceite. Por referirnos a las ayudas, en la situación actual pueden ser de dos tipos: la ayuda a la producción y la ayuda al consumo.

La ayuda a la producción se hace efectiva de dos formas. Por un lado, se concede a los agricultores cuya cosecha media sea al menos igual o superior a $500 \mathrm{~kg}$. de aceite por campaña, en función de la cantidad de aceite realmente producida. En este caso, los agricultores pueden percibir una ayuda teórica de unas 230 pesetas por kilo de aceite realmente producido en almazara. A los pequeños productores, los que no llegan a producir 500 $\mathrm{kg}$. de aceite por campaña, la ayuda se concede en función del número de olivos y del rendimiento medio de cada zona, fijado a tanto alzado, a condición de que las aceitunas hayan sido trituradas. Esto supone el pago de una subvención segura por árbol, al margen de la producción. Estos pequeños productores reciben además desde la campaña 91/92 una ayuda de 3 ECUS por cada 100 kilogramos de aceite producidos. En España este segundo grupo recibe sólo el 9\% del total de las ayudas. Porque en España, la producción teórica de este colectivo no llega al $7 \%$ del total. Italia, en cambio, produce por este sistema el $60 \%$ de la cifra de su producción oficial. Este sistema va acompañado de la fijación de una CMG, el llamado mecanismo estabilizador, que hasta la campaña 96/97 era de 1.350.000 toneladas para toda la UE, con exclusión de la produc- 
ción de los pequeños. Se penalizan los excesos sobre esa cantidad en un $\%$ igual al exceso sobre la cifra apuntada.

La ayuda al consumo tiene por objeto favorecer el consumo interior a un precio competitivo con los demás aceites concurrentes en el mercado. Se concede a las empresas envasadoras de aceite de oliva reconocidas, repercutiendo sobre el precio al consumo. Se ha ido reduciendo de manera progresiva, y se calcula como la diferencia entre el precio indicativo y el precio representativo de mercado cuando aquél sea superior. La cuantía ha descendido tanto que algunos envasadoras prefieren no solicitarla para evitar los controles que conlleva.

\section{Las primeras propuestas de modificación}

El borrador de 1996

En 1996 la Comisión de la UE, a propuesta del Comisario de Agricultura Franz Fischler, elaboró un borrador de proyecto de una nueva OCM en el que se eliminaba el precio de intervención, la ayuda a la producción y la ayuda al consumo y se establecía un sistema único de ayudas al árbol, estableciendo un número fijo de árboles a primar en cada estado miembro.

La opción de ayuda por árbol implicaría que las ayudas a la producción y al consumo existentes hasta ahora se sustituyen por ayudas directas al olivo a tanto alzado, con número de olivos limitado por estado miembro. Para España el número total de árboles sería de 166,5 millones, y recibirían -por situarse en la denominada zona A-4,5 ecus por árbol. Cada estado miembro productor aplicará un sistema de control para asegurar que las condiciones para las concesiones de ayuda sean cumplidas; además, tendrá que establecer datos de un Sistema de Información Geográfica sobre el olivar, por el que se controlará la localización de los olivos declarados de acuerdo con un sistema de localización de parcelas.

Dado que en la actualidad esta propuesta ha dejado de estar vigente, prescindimos de su exposición detallada. Además se proponía la neutralidad presupuestaria, es decir, evitar cualquier incremento del gasto; por eso mismo, la CMG debería ser mantenida y no incrementada. 
El impacto de los cambios

La propuesta de reforma provocó el rechazo unánime de la administración española y de la totalidad del sector, ya que la concesión de una ayuda por olivo conllevaría unas repercusiones profundamente negativas.

En primer lugar, generaría una fuerte desmotivación en el agricultor, que recibiría la misma cuantía de subvención independientemente de que el olivo produzca o no, lo cual fomentaría el abandono de las buenas prácticas agrícolas -labores del suelo, lucha contra las plagas, poda, mantenimiento de la tierra eliminando malas hierbas, etc.- y se traduciría en una grave pérdida cuantitativa y cualitativa de la cosecha. Esto acarrearía una pérdida considerable de empleo, en zonas donde existe un altísimo nivel de desempleo y donde porcentajes muy elevados de la población viven del olivo. En el aspecto medioambiental también produciría graves consecuencias, dado que una manera de luchar contra la erosión y la desertificación es el mantenimiento de un sector próspero que practique un adecuado cuidado del terreno en las zonas propicias para el olivar.

Al fijarse un montante de ayuda financiera global para cada país, estimada en función de una CMG, si se diera una mayor producción ello llevaría consigo, obviamente, una subvención menor por kilogramo de aceite producido, permaneciendo idéntica la ayuda global... Por la misma razón, en caso de mala cosecha, o en los años bajos de la tradicional «vecería», la subvención por kilo ascendería de forma equivalente: este es un extremo que no se suele tener en cuenta.

Por último, los eventuales cambios en el sistema de intervención llevarían consigo que se perdería el recurso a la venta de posibles excedentes a los organismos europeos de intervención, procedimiento que permite garantizar unos ingresos mínimos en caso de exceso de oferta.

La renuncia a la ayuda al consumo -que cobran los envasadores, y que asciende a 20 ptas. por kilo de aceite, sobre un precio de venta al público de 400-450 ptas. $/ \mathrm{kg}$.- parece más tolerable, teniendo en cuenta sobre todo que se presta especialmente al fraude, tal y como reconocen las mismas organizaciones profesionales del sector. 
Entrando en más detalles, simulaciones muy precisas realizadas en ETEA, tanto en estudios de explotaciones concretas analizadas con detenimiento (análisis de casos) como en una muy amplia y representativa muestra de explotaciones olivareras, demuestran que el impacto de la reforma en el sector, según las distintas hipótesis contempladas, sintetizando mucho, es el siguiente:

a) Sea cual sea el escenario contemplado (se contemplaron varios), el olivar marginal, menos productivo, normalmente en explotaciones más pequeñas, dificilmente podría soportar reducciones importantes de precios y subvenciones.

b) Ese mismo colectivo de explotaciones de olivar «marginal» es precisamente el único que resultaría favorecido por un sistema de ayuda al árbol: las explotaciones más pobres, menos productivas, y con menor consumo de mano de obra (por producir menos cantidad por árbol) serían las más beneficiadas.

c) Las plantaciones modernas de olivar de secano, de pie único y de alta densidad, que admiten mayor nivel de mecanización $y$, por ende, consumirán menos mano de obra, serían beneficiadas igualmente por la ayuda al árbol.

d) El sector productivo de secano más tradicional, con olivos de 3-4 pies y densidades menores a 100 árboles por ha (la mayor parte de la superficie plantada, la que más mano de obra requiere para la recogida) se vería perjudicado notablemente en sus márgenes económicos en el caso de la ayuda al árbol.

e) Un sistema de ayuda mixta (50\% al árbol y 50\% a la producción), aun con ser administrativamente complicado de establecer, tendría sin duda consecuencias menos nocivas para los olivares productivos tradicionales y elevaría los márgenes de los olivares marginales, aunque reduciría algo los márgenes de las plantaciones recientes más intensivas.

\section{Las razones de la reforma}

Esta reforma de la OCM del aceite de oliva no se aborda aisladamente, sino en el más amplio contexto de la reforma global de la PAC, un contexto 
muy turbulento caracterizado por profundas modificaciones en las líneas maestras de la política tradicional. Pero además, hay razones que se refieren más especificamente al caso del aceite. Veamos unas y otras por separado.

En el contexto de la reforma de la PAC

Como es bien conocido, la PAC ha sido la política sectorial dominante desde los inicios de las Comunidades Europeas. Durante décadas ha absorbido mucho más de la mitad de su presupuesto de gastos, que se destinaban a la protección agraria, lo que no sucedía naturalmente con ningún otro sector productivo. Entre otros objetivos, se pretendía ante todo incrementar notablemente la productividad y la producción agrícola, partiendo de la situación de déficit europeo de productos alimenticios que caracterizaba la década posterior al final de la segunda guerra mundial.

Ya en los años 70 aparecieron síntomas preocupantes consistentes en la proliferación de excedentes de cereales, productos lácteos, azúcar y carnes, que implicaban un crecimiento desproporcionado del gasto comunitario a la vez que ponían en evidencia los efectos perversos de una política protectora y productivista a ultranza. De alguna manera la PAC tradicional empezaba a ser víctima de su propio éxito.

Además de esas razones, en el interior de la CEE se planteaban graves problemas derivados de la desigual distribución de las ayudas (a favor de determinados productores: los grandes; de determinados países: Francia, ante todo, pero también Alemania, Holanda etc.; de determinados sectores: los productos llamados continentales); junto con ello se producían indeseables efectos de degradación medioambiental, derivados del avance de la "frontera agrícola», ya que las tierras de cultivo -muy rentables por las subvenciones- tendían a adueñarse de áreas antaño dedicadas a prados y pastizales y a superficies forestales. Además, la intensificación productiva incrementó la contaminación, tanto por la vía del uso desmedido de abonos y pesticidas, como de la acumulación y concentración de deyecciones animales en las áreas ganaderas.

Desde fuera no iban mejor las cosas para la PAC tradicional: en la Ronda Uruguay del GATT de los primeros años 90 los Estados Unidos, 
apoyados por muchos países que veían frenadas sus exportaciones de productos agrarios hacia la CEE y se veían perjudicados por las exportaciones de excedentes comunitarios, presionaron tremendamente a la UE para llegar a un acuerdo de profunda disminución de las ayudas agrarias.

En ese doble contexto de dificultades internas y externas hay que situar la reforma de la PAC. Esta reforma, cuyo comienzo se sitúa en 1992 con las iniciativas del anterior comisario Mac Sharry, tuvo una primera ola de medidas consistentes en "desvincular» (es el famoso "découplage») las ayudas de la producción en los cultivos de cereales, oleaginosas y proteaginosas, así como en productos ganaderos y en azúcar y garantizar las rentas de los agricultores mediante las llamadas "ayudas directas». Los años transcurridos demuestran que, si bien se ha conseguido frenar la producción y bajar los precios, así como disminuir la protección en frontera de entrada y de salida, el gasto agrario en ese bloque de productos ha seguido creciendo.

La contención del gasto agrario era el argumento principal a favor de la reforma de la PAC. Un problema ulterior es la distribución de ese gasto agrario entre los países miembros: pues bien, como veremos más adelante, podemos estar seguros que ante un frente mediterráneo dividido, y dado como se toman las decisiones en la UE, las reformas futuras irán en la línea de reforzar a los productos continentales en perjuicio de los mediterráneos.

Por otra parte, las medidas agrarias contempladas en la Agenda 2000 (ese vasto programa de reformas ya mencionado en el que se inscribe la reforma de la OCM del aceite de oliva) no son más que una prolongación de la Reforma de la PAC, que incorpora ahora -entre otras cosas-las previsiones relativas a la ampliación de la UE a los países del Este; esto aumentará sin duda el volumen de recursos necesarios para financiar al sector agrario, cosa a la que se resisten los países contribuyentes netos al presupuesto comunitario, sobre todo Alemania.

El caso particular del aceite: el fraude

Uno de los argumentos esgrimidos a favor de los cambios sugeridos en la OCM del olivar consiste en la conveniencia de prevenir el fraude en lo relativo al cobro de las subvenciones al aceite. 
Como ya hemos expuesto, la OCM vigente para el aceite de oliva prevé un doble sistema de ayuda a los productores de aceite. Los pequeños productores (menos de $500 \mathrm{~kg}$. de aceite) reciben una ayuda en función de su producción estimada; los productores con más de $500 \mathrm{~kg}$. reciben una ayuda en función de su producción real. En tales condiciones, el fraude más generalizado -especialmente en Italia, por la sencilla razón que en aquel país la mayoría de los productores son pequeños-consiste en que el pequeño productor recibe la ayuda, vende su cosecha a un productor grande y éste cobra la subvención tanto por la producción propia como por la "ajena», subvención esta última que es compartida entre ambos.

Dicho esto, es preciso añadir que, según la propia Comisión, el fraude en esta OCM del aceite es similar a la que arrojan los llamados cultivos COP (cereales, oleaginosas de siembra y proteaginosas).

\section{La estrategia negociadora. El «frente mediterráneo»}

Los mecanismos de decisión de la UE

Quizás no venga mal recordar que el Consejo de Ministros es el órgano legislativo comunitario, y que decisiones como las que nos ocupan se toman en su seno por mayoría cualificada; lo cual supone que para poder bloquear, por ejemplo, la llamada «reforma Fischler» es preciso aunar 26 votos sobre un total de 87, con el fin de impedir que se consiga la mayoría cualificada que asciende a 62 votos. Dado el número de votos por país, es evidente que si se consigue formar un voto común mediterráneo, (España 8 votos; Italia, 10 votos; Portugal y Grecia 5 votos) se habrá conseguido una minoría de bloqueo. Se equivocan, por tanto, a nuestro juicio, los que han desarrollado una estrategia consistente en oponer los intereses italianos y españoles.

Una división entre los países productores puede tener resultados desastrosos para los oleicultores europeos. La división del frente mediterráneo sólo conseguiría que los productos citados ya reformados, llamados continentales -que cuentan en principio con una defensa unitaria de los países «del norte»- salgan reforzados, frente a los mediterráneos (frutas $y$ hortalizas, vino y aceite de oliva), pendientes de sus respectivas reformas. 
Por otra parte, el protagonismo del «frente mediterráneo» se hace cada vez más difícil de mantener si se tiene en cuenta la evolución de la UE. En efecto, cuando España y Portugal entraron en ella en 1986, detrás de Grecia que lo había hecho 5 años antes, el centro de gravedad geográfico, político y económico de la Comunidad Europea se trasladó claramente hacia el Sur. El Mediterráneo cobró protagonismo en el seno de la Comunidad, en todos los sentidos, desde luego en el económico. Sin embargo, la ampliación de la UE en 1995 con la entrada de Austria, Suecia y Finlandia desplazó hacia el norte dicho centro de gravedad. Y en la coyuntura actual, todas las miradas están pendientes de la futura ampliación hacia los países del Este - desde luego a Polonia, República Checa y Hungría- con el consiguiente desplazamiento hacia el noreste de dicho centro de gravedad. La atención de la mayoría de los países, y desde luego de los llamados contribuyentes netos al presupuesto comunitario, no se centra ya en los países del sur de Europa. Este es un proceso irreversible: en efecto el frente mediterráneo está bloqueado y no puede crecer, sencillamente, porque no quedan países al sur de la UE hacia donde ampliar su ámbito...

Las lecciones de un voto parlamentario

Como es bien conocido, el eurodiputado de IU Salvador Jové, presidente de la Comisión de Política Agraria del Parlamento Europeo, elaboró un informe que sirvió de base al dictamen que emitió el Parlamento el 18 de diciembre de 1997 y que se manifestó contrario a las ideas básicas de la primera propuesta del comisario Fischler y básicamente a favor de las propuestas españolas incluso con el apoyo italiano: dicho en pocas palabras, no introducir la ayuda al árbol, mantener el sistema de intervención y la ayuda a la producción y elevar el techo de la CMG a 1.800.000 toneladas.

Este triunfo en el Parlamento - con una votación holgadamente favorable de 272 a favor, 119 en contra y 23 abstenciones- sólo fue posible por el apoyo de diputados de las formaciones europeas conservadores (Partido Popular europeo) y el de los socialistas españoles e italianos. El gran bloque opositor, muy activo precisamente en la Comisión de Agricultura, 
está liderado -cómo no-por los laboristas británicos, cuya estrategia permanente (al igual que sus paisanos conservadores) va en la línea de desmantelar progresivamente la PAC, siguiendo una constante de los gobiernos británicos desde la adhesión de Gran Bretaña.

\section{El «informe Jové»: ¿Una postura más moderada?}

Contra dicha lógica, el señor Jové luchó, hasta la extenuación propia, y sobre todo de los diversos grupos políticos del Parlamento Europeo, que convencidos votaron por elevada mayoría a favor de su informe. Según tuvimos ocasión de escucharle personalmente el 20 de febrero de 1998, el mismo Salvador Jové resume su postura del siguiente modo:

$1^{\circ}$. Hay que crear un frente mediterráneo unido (Portugal, España, Italia, Grecia e incluso Francia). Todos los estados de dicho frente deben considerar que sus intereses quedan salvaguardados en lo esencial: eso supone una cierta dosis de flexibilidad en la negociación y el abandono de cualquier postura "de órdago», de "o todo o nada». Pero - añadimos nosotros- no es tan fácil "ganarse» a los italianos y a los griegos, cuando nuestro país va a doblar su producción en menos de una década...

$2^{\circ}$. Nunca en el sector del olivar, y al menos hasta la fecha, ha habido problemas de excedentes.

$3^{\circ}$. El fraude en el sector es similar al de otros productos agrarios, en torno a un $2 \%$ (habida cuenta que este porcentaje es sobre un total de ayudas que representan el $5 \%$ del gasto agrario, frente a otros productos que doblan o triplican su representación en el gasto agrario comunitario).

$4^{\circ}$. Con la vigente CMG (1.350.000 toneladas), anterior a la reforma, se protege tan sólo el $75 \%$ del consumo de aceite de oliva en la Unión Europea, estimado en 1.800.000 toneladas. Por tanto tampoco puede considerarse satisfactoria la cifra de 1.550 .000 toneladas de la propuesta «reformada».

$5^{\circ}$. No todos los cultivos pueden tratarse por la política agrícola común del mismo modo, no hay una ley universal que sirva para todos los cultivos. 
$6^{\circ}$. Gracias al debate parlamentario en torno a la problemática del aceite de oliva, el Parlamento Europeo, órgano democrático por excelencia de la Unión aunque con pocos poderes reales, adquirió una relevancia significativa y ofreció un importante espaldarazo a la posición española. Es necesario además que se produzca un gran debate parlamentario transparente sobre el conjunto de la problemática del sector agrario, sin tener presentes los beneficios partidistas e incluso estatales: para eso el Parlamento europeo constituye el foro más adecuado.

Desde el punto de vista de la estrategia negociadora, compartimos su planteamiento acerca de la absoluta prioridad del mantenimiento de la gran unidad existente hasta la actualidad de todo el sector del aceite de oliva, de políticos de todo signo y en general del país en torno a un producto agrario y en defensa del mismo. Esto es todavía es más llamativo si se observa que países productores pertenecientes a la UE (Italia, Grecia y Portugal) no lo han logrado.

En segundo lugar, Jové señala que la unión no debe ser sólo de los españoles frente a Fischler y frente al resto de Estados miembros de la Unión Europea, sino de los países mediterráneos entre sí en defensa de sus cultivos especificos y no contra los otros cultivos del resto de países de la Unión, es decir, no se trata de unirse en contra de nadie ni de nada, sino en defensa de los productos agrarios específicos de los Estados del Sur de Europa.

Por último, la filosofía del informe Jové se basa en la constatación de que las reformas acaecidas hasta ahora no han conseguido de hecho imponer la lógica de los últimos Comisarios de Agricultura europeos, pues aunque se ha contenido el gasto agrario, todavía sigue siendo el más importante del presupuesto comunitario, y sigue siendo igual de injusto que lo era antes de tales reformas (el $80 \%$ de las ayudas va a parar a manos del 20\% de los productores, los más ricos). Es más, según lo que se avecina a través de la Agenda 2000, la situación no parece que vaya a cambiar, pues se propone un incremento de más de 6.000 millones de Euros (del año 2000 al 2006) para los productos denominados continentales (leche, cereales-oleaginosas y carne de vacuno), casi el triple del gasto total actual en el sector olivarero de toda Europa que no se incrementaría nada en el mismo periodo... 


\section{La nueva propuesta de la Comisión}

Según las informaciones disponibles en el momento de redactar el presente editorial, la propuesta de la Comisión del 18 de marzo se basa en varios pilares básicos: abandono temporal de la idea de la ayuda al árbol durante tres años de transición, aumento de la CMG hasta 1.562.400 toneladas (aumento de 200.000 toneladas), abandono de los sistemas de intervención, reparto por cuotas nacionales y prohibición de nuevas plantaciones.

Si se mantienen las 1.562.400 toneladas de la propuesta citada y la subdivisión en cuotas por países, a España corresponderían 625.210 toneladas de aceite con derecho a subvención. Esta cifra también ha sido rechazada por parte española. Pero hay que reconocer que no es descabellada a la vista de la serie histórica que hemos reproducido más arriba (bien elocuente, por cierto). Las razones del rechazo hay que buscarlas, más bien, en las últimas excelentes campañas y, sobre todo, en las perspectivas de incremento debido a la multiplicación de nuevas plantaciones altamente productivas; acaso más del 30\% de la superficie actual está aún lejos de llegar a su madurez productiva. Por otra parte, estos dos últimos años de buenas cosechas no se deben sólo a la casualidad, ni a una climatología benigna, sino también a que se cultiva cada vez mejor. El alto precio del aceite en las campañas anteriores y las ayudas al producto hacen que se mimen las plantaciones al máximo. Pero cabe preguntarse si es deseable una OCM que favorezca un aumento de la producción.

Desde el punto de vista español, hay algunos puntos que ahora se proponen como irrenunciables: la fijación de la CMG en los niveles reales de consumo comunitario situada en torno a 1.800.000 toneladas, muy superior al 1.350 .000 actualmente vigente y al millón y medio de la propuesta citada; ello permitiría a España disponer de una cuota cercana al millón de toneladas; asimismo sería preciso mantener las ayudas a la producción, para evitar la desactivación del sector y el aumento del desempleo.

Sin embargo nos sorprende que nadie mencione el hecho perfectamente documentado de que en un «Documento de consenso sobre la reforma de 
la OCM del aceite de oliva (suscrito por el sector productor e industrial del aceite de oliva en España)» y que aparece como Anexo 2 del citado informe del Consejo Económico y Social, al afirmar la necesidad de aumentar la CMG «ya que ésta ha quedado bastante desfasada» se menciona como producción media para el año 2000 la que proponían a la sazón los estudios del (COI) Comité Oleícola Internacional «en los que se fija una producción media en la Unión Europea en el horizonte del año 2000 de 1.550.000 toneladas». Sobra todo comentario.

Otra cuestión en la que la postura española si que se mantuvo siempre constante fue la negativa a la subdivisión de la cuota global en cuotas nacionales: "Dicha CMG deberá ser global a nivel de la UE y en ningún caso deberá estar contingentada por países», rezaba el documento de consenso que acabamos de citar. Por consiguiente, éste es un elemento de la última propuesta de la Comisión unánimemente rechazado.

\section{Hacia una respuesta adecuada por parte de España}

Hacer una cuestión de Estado y lograr la unidad de los productores

Como en otros ámbitos más delicados de la vida nacional (terrorismo) una vez más hemos asistido al espectáculo lamentable del intento sistemático de utilización de un asunto de interés nacional en beneficio de uno u otro partido. Dado el diferente color político de los gobiernos nacional y andaluz, no han faltado enfrentamientos dialécticos sobre la actitud de unos y otros en la defensa del olivar y el aceite. Cada cual ha intentando convencer a la opinión pública de que su formación política es la que verdaderamente defendia los intereses afectados. También aqui huelgan las palabras para calificar este comportamiento político.

Pero hay más. Como ya se ha indicado, una de las bazas de la «batalla del aceite de oliva» ha sido la decisiva unidad de acción de los productores conseguida en particular en el ámbito de la «Mesa Nacional del aceite» en la que están representados todos los subsectores interesados. Y es que, en los temas de la política agraria europea la experiencia demuestra hasta la saciedad que la unión de los productores, sea en el sector que sea, es siempre rentable; es más, los gobiernos y partidos políticos respectivos no 
tienen autoridad moral para imponer - en el Consejo de Ministros de la UE-sus puntos de vista si el sector está dividido. Por eso los partidos tienen que reconocer que la politización de estos temas es nefasta y buscar urgentemente el acuerdo con los productores: cualquier división en estos frentes beneficia a los contrarios.

Una posible OCM satisfactoria

Comprometiéndonos un poco más y puestos a exponer de forma sintética los rasgos que consideramos deberían caracterizar una OCM del aceite que fuera justa y satisfactoria para los intereses españoles, sugerimos los siguientes:

- Desechar definitivamente la posibilidad de sustituir la ayuda a la producción por una ayuda exclusiva al árbol, que tendría funestas consecuencias sociales y desincentivaría las mejoras productivas.

- No distinguir entre países productores asignando cuotas, ya que eso supone un nuevo caso de renacionalización de la PAC (como ya ocurrió con la leche). La corresponsabilidad es para todos los productores comunitarios.

- Eliminar la ayuda a tanto alzado a los pequeños productores, puesto que ésta no debe discriminar por la cantidad producida; todos deben, además, justificar su producción real.

- Realizar un censo oleícola actualizado y real, que incluya número de árboles y hectáreas dedicadas al cultivo. Es una medida esencial para combatir el fraude.

- Incrementar la CMG adecuándola a la demanda del producto, esto es, consumo interno + exportaciones - importaciones. Según los expertos, es de prever un incremento del consumo global.

- Limitar la cuantía máxima de ayuda a percibir por propietario o explotación en función de criterios de renta.

- Vincular la ayuda a la mejora de la explotación y a la diversificación de actividades dentro del medio rural.

- Mantener el mecanismo de intervención pero introduciendo un cupo máximo de compra por la UE, con un doble objetivo: incentivar la búsqueda de nuevos mercados por un lado, y, por otro, mantener un 
stock privado de seguridad entre campañas.

- Introducir una prima especial por calidad del aceite producido.

- Limitar la ayuda al olivar plantado antes de una fecha determinada con objeto de frenar su excesivo e incontrolado crecimiento. En cualquier caso, es preciso controlar el incremento desordenado de nuevas plantaciones; y los propios productores deben tomar poco a poco la responsabilidad del control de la oferta, como ocurre en otros sectores productivos y en otros países.

- Suprimir la ayuda al consumo y dedicarla a promocionar el consumo de aceite en mercados exteriores. Un incremento de la demanda exterior (todavía muy limitada) resolvería gran parte de los problemas del sector y disiparía el temor a una futura reconversión motivada por el auge excesivo de las nuevas plantaciones.

- Dedicar una pequeña parte de los fondos comunitarios destinados al sector a realizar estudios socioeconómicos sobre este producto para conocer la realidad del cultivo, y tomar decisiones de política agraria basada en un análisis microeconómico y no sólo de grandes cifras.

El control de la oferta: disciplina de los productores

No estamos, ni mucho menos, ante el primer episodio conflictivo de dimensión estructural (no meramente coyuntural) que afecta a la producción del aceite de oliva precisamente desde el lado de la oferta. No viene mal recordarlo.

Como todos los conocedores del sector recuerdan muy bien, no hace tanto tiempo que tuvo que ser puesto en marcha por el gobierno español un vasto programa de "reconversión» del olivar (nombre que recuerda al duro ajuste industrial de los años 80, con el que tiene claros paralelismos). En efecto, mucho antes de la entrada de España en la UE, y ante lo que se consideraba una auténtica "crisis» del sector, debida a un excesivo incremento de las plantaciones y a una falta de rentabilidad del cultivo, en 1972 se puso en marcha un «Plan de Reestructuración y Reconversión del Olivar» encaminado a reconvertir el olivar marginal y a fomentar el olivar productivo. No fue ajeno a este fenómeno el incremento nacional del consumo del aceite de semillas, provocado por la gran diferencia de 
precios con el de oliva y la incapacidad del sector productor para cubrir sus costes y competir en precios bajos con aquellos aceites de menor calidad. En pocas palabras: se trataba de un masivo programa subvencionado de arranque de olivos.

Hay que saber que, en la actualidad, el consumo de aceite de oliva es más inelástico que hace 20 años; a ello ha contribuido decisivamente la mejora en el nivel de vida de los ciudadanos, que se resisten a consumir aceites de inferior calidad a pesar de las subidas de precio del de oliva, por el auge de la dieta mediterránea. Sin embargo, al observar el incremento masivo de plantaciones que está teniendo lugar en los últimos tiempos, no es ningún disparate pensar que una nueva reconversión como la de los años 70 pudiera llegar a ser necesaria en los próximos años...

No es éste el momento de analizar los resultados de aquel proceso, que duraría hasta finales de los años 70. Sírvanos su recuerdo para constatar que el incremento incontrolado y desordenado de las plantaciones puede constituir un grave problema por el lado de la oferta.

Pero además, con motivo de estas recientes batallas se ha recordado, con razón, que antes de la entrada de España en la Comunidad Europea, durante décadas los productores de aceite de oliva de Andalucía vendieron ingentes cantidades de su producción, a granel, a los envasadores italianos que utilizaban estas producciones para incrementar su volumen aparente de producción, y para justificar el cobro de mayores subvenciones. Los productores españoles veían como este sistema les simplificaba mucho la tarea de transformación y comercialización de sus propios productos, aunque obviamente dejaban de percibir la parte más sustancial del valor añadido del sector. Por otro lado, el sector industrial cayó poco a poco en manos de empresas multinacionales extranjeras, desapareciendo en la práctica el capital español del mismo. De aquellos polvos vienen estos lodos, y no se pueden ignorar. Ahora bien, aunque la distribución está en manos extranjeras, aún queda margen de actuación: la producción está en manos españolas, ya que las almazaras son cooperativas o particulares, pero prácticamente siempre españolas; algo se puede hacer: el sector debe reforzar su papel en los circuitos del producto y en la negociación del valor añadido.

Por tanto, además de luchar por el mantenimiento de las subvenciones, 
hay que trabajar en estos dos frentes: control de las plantaciones y mejora de la calidad.

Por una parte, será preciso introducir una mayor disciplina en el sector productor, ante todo en lo referente al control de las plantaciones. Es urgente controlarlas e ir adaptándolas a la evolución de la demanda. Es un hecho conocido que se está produciendo una "fiebre» de plantación de olivos, lógica si se tienen en cuenta varias circunstancias: a) es un cultivo cuyo producto se ha apreciado y, sobre todo, que ha visto multiplicada por 20 su ayuda unitaria en una década; b) por otro lado, se está desincentivando la siembra de cultivos como cereales y oleaginosas de siembra, ya que los precios están bajando y existe la obligación de retirar del cultivo parte de las fincas, lo que no sucede con el olivar; c) por último, se ha producido una crisis en un cultivo en cierto modo "rival» del olivar: el viñedo. Las ayudas al arranque han liberado nuevos terrenos para cultivar, y prácticamente subvencionar las nuevas plantaciones de olivar. También es cierto que se han plantado olivos con frecuencia en terrenos inadecuados.

Asimismo debe crecer el esfuerzo destinado a mejorar la calidad del producto y a la organización de los productores frente a las multinacionales que dominan el sector del envasado y la comercialización.

Del «cultivo social» a la «maldición del monocultivo»

Pero la reflexión debe ir más lejos. Del olivar se dice con frecuencia-como se decía antes del algodón y de la remolacha-que es un cultivo social, porque «da mucho empleo». Es cierto que en las zonas olivareras las faenas relacionadas con la recolección, acopio y primera molturación del fruto del olivo, provocan una intensa ocupación en los meses de diciembre a marzo, según las zonas y la coyuntura climatológica. Para no hablar de memoria, las cifras más realistas hablan de un número de jornales entre 40 y 50 millones. De ellos un número creciente es asegurado por inmigrantes, con un creciente nivel de ilegalidad que todo el mundo conoce, pero del que se prefiere no hablar.

Pero ese planteamiento, un tanto primario, debe dar lugar a otras elementales consideraciones; desde tiempo inmemorial el monocultivo es 
un mal social, una maldición; frente a un par de meses de empleo, el monocultivo olivarero genera 10 meses de desempleo masivo, sobre todo en las zonas donde su presencia es avasalladora, lo que ocurre en muy numerosas, extensas y pobladas comarcas de las provincias de Jaén, Córdoba y Sevilla.

Cualquier monocultivo es también un mal económico, una situación dañina para la región en que se inserta. Sea industrial o agrario: da igual. Para la comarca de El Ferrol, el monocultivo de la industria naval; para la de Sagunto el de la industria siderúrgica; para Jaén el del olivar. Y la razón principal es que monocultivo significa, dicho vulgarmente, "poner todos los huevos en una misma canasta». Pero hay una diferencia a favor del monocultivo industrial: que mientras dure la demanda (y si no llegan crisis radicales como la de los años 70 en los casos aludidos de El Ferrol y Sagunto) la industria da trabajo todo el año. El olivar, no.

Aparte consideraciones estéticas, medioambientales, paisajísticas, o nostálgicas, el olivar es una maldición mediterránea. No se encontrará en ningún rincón del Mare Nostrum una comarca predominantemente olivarera que haya diversificado sus fuentes de rentas y aprovechado las rentas del árbol de los dioses para impulsar la generación alternativa de empleo. Razones económicas elementales lo explican: la implantación de producciones diversificadas en las áreas olivareras no puede más que encarecer los salarios, que representan por término medio (y según las producciones) un $60 \%$ de los gastos totales del cultivo. Y estamos hablando de un cultivo en el que los costes de cosecha son la parte sustancial del coste total, donde además la mecanización ha ido muy por detrás de la de otros sectores productivos, entre otras razones, por motivos de índole tecnológica.

\section{Ampliando el campo de visión: más allá de las subvenciones}

El mundo rural a la búsqueda de un argumento

Los apasionados debates en curso -el del aceite no es el único, aunque en nuestro entorno adquiera particular virulencia- y los cambios que están acaeciendo en las políticas agrarias europeas, con sus consiguientes y dramáticas repercusiones en España en general y 
en Andalucía en particular, aparte de otras cuestiones de carácter coyuntural, están poniendo de manifiesto de forma clamorosa la necesidad de afrontar el futuro del mundo rural andaluz con perspectivas más globales y duraderas.

En efecto, una parte importante del mundo rural -en particular andaluz- en términos generales, parece haber perdido su «argumento» agrarista tradicional. Como cualquier otro sector productivo, en un entorno caracterizado por su enorme complejidad, necesita de un argumento aglutinador claro que permita armonizar las decisiones individuales y otorgar una mayor capacidad al sistema en su conjunto.

Ciertamente, el sistema rural es variado, complejo y multifuncional; cualquier simplificación a un ámbito sectorial, o regional, tiene el peligro de ignorar otros aspectos de su rica y variada realidad. Ahora bien, de una manera general, y aun con el riesgo de simplificar, puede decirse que una parte importante del sistema rural regional ha encontrado en lo que nos atrevemos a llamar «la caza de las subvenciones comunitarias» a determinados sectores agrarios su argumento fundamental, su razón de ser, su caballo de batalla.

Las subvenciones, un arma de doble filo

Más aún, la opinión generalizada de los ciudadanos es que España ha obtenido de la UE sobre todo subvenciones. La imagen que capta el gran público acerca de la Unión es que se trata de una gigantesca fuente de ayudas financieras y que las batallas europeas son batallas por los fondos comunitarios. Es obvio que se trata de un grave error de enfoque: para bien y para mal la Unión Europea, hoy por hoy, es un gran mercado único, relativamente protegido (cada vez menos), de la competencia del exterior, en rápida evolución hacia una zona monetaria única...

Sin poner ahora en cuestión la legitimidad global de la ayuda al sector agrario y al mundo rural, que nos parece incuestionable, sin embargo es preciso afrontar esa realidad con la mayor honestidad intelectual posible. Algunas cifras nos ayudarán a ver más claro y a preguntarnos si es éste el mejor camino para movilizar las energías del mundo rural de nuestra región en la dirección adecuada. 
En efecto, los agricultores de Andalucía -por referirnos a la región más afectada por la reforma en curso- reciben anualmente por encima de 200.000 millones de pesetas en forma de ayudas a la agricultura, lo que representa nada menos que alrededor del 30\% de la renta agraria regional; nos parece legítimo preguntar si esa inyección anual se traduce efectivamente en el desarrollo del medio rural andaluz y, sobre todo, en una contribución significativa a paliar el principal problema regional: las elevadísimas tasas de desempleo. Como es sabido, precisamente esas subvenciones están sobre todo concentradas -en nuestro entorno más cercano- en subsectores como olivar, cereales y girasol.

Por provincias, la desigualdad en el reparto de las subvenciones agrarias es patente: a causa de su especialización productiva, las subvenciones a los agricultores de Almería representan menos del 5\% de la renta agraria provincial, frente al 35-40\% para Córdoba, el 30-35\% para Jaén, o (según los años) entre el 30-50\% para Sevilla. Sin pretender establecer ninguna relación de causa a efecto, no puede menos de llamar la atención el hecho de que, paradójicamente, sean precisamente las provincias menos subvencionadas (Almería, Huelva y Málaga: por ese orden) las que presentan las menores tasas de desempleo total y agrario -con ser altos- en la región...

A escala de explotación, las perspectivas no son más alentadoras. Por ejemplo, según los datos publicados correspondientes al año 1997, las ayudas a las explotaciones productoras de trigo duro se concentraban de forma llamativa; en efecto, el 91,6 por ciento de los beneficiarios, poseedores de explotaciones inferiores a $50 \mathrm{Ha}$, recibian el 45,7\% de las ayudas del trigo duro; por su parte, el 8,4\% de las explotaciones, las mayores, las superiores a 50 ha, acaparaban el 54,3\% de las subvenciones. En el caso del olivar, investigaciones fehacientes realizadas en la Universidad de Córdoba (ETEA y Escuela de Ingenieros Agrónomos) y patrocinadas por la propia Junta de Andalucía - a partir de encuestas directas a un número significativo de explotaciones-demuestran que el grado de concentración de las ayudas responde casi exactamente al famoso esquema 80-20 del Informe Mac Sharry: aproximadamente el 20\% de las explotaciones olivareras más grandes, reciben el $80 \%$ del total de las subvenciones al olivar; dicho más claramente, las subvenciones se 
concentran en los estratos de productores más ricos. Por tanto, según el modelo actual, las ayudas a la producción, desde la óptica de la distribución de la renta, resultan regresivas. ¿Qué ocurriría en un sector industrial si el Estado concentrara las subvenciones en las empresas más ricas y menos necesitadas de ayuda?

La presencia masiva de las subvenciones de todo tipo, especialmente en el sector agrario, ha generalizado indebidamente en Andalucía una cultura muy peculiar: nuestra región ha evolucionado, de forma creciente $y$ alarmante, hacia un modelo que ha sido calificado acertadamente «tierra de asistencia»; y sin embargo existen en Andalucía ejemplos de zonas que han dado pasos de gigante, en la evolución de su cultura empresarial, transformándose en «territorios de iniciativa». Basta para convencerse de ello echar una mirada a la agricultura almeriense, o a determinados enclaves industriales o de servicios de la costa y de determinados pueblos y ciudades del interior. En ese escenario, Andalucía aparece como una región obsesivamente dependiente de las ayudas externas.

Diversificar la economía en el medio rural

El principal problema de Andalucía es el paro. Si se asume esa premisa, el reto de la región consiste en la creación de empleo. Al nivel actual de las tecnologías, no es de esperar que dicha creación de empleo pueda realizarse en la actividad productiva propiamente agraria: el empleo agrario, verosimilmente, tendrá que seguir bajando. Pero a la vez hay que frenar el despoblamiento de las zonas rurales que acarrea pérdidas irreparables y eleva los costes de aglomeración en los medios urbanos ya congestionados. Es preciso diversificar las fuentes de empleo en el medio rural: industrias agroalimentarias, artesanías de todo tipo, actividades medioambientales y conservacionistas, turismo rural, proliferación de residencias secundarias individuales y colectivas, recuperación del patrimonio rural, y tantos otros, son caminos que deben ser explorados con mucha mayor decisión; existen planes y programas al respecto cofinanciados al amparo de las propias iniciativas comunitarias (programas Leader) $o$ regionales.

Podemos estar seguros que para ese género de actividades no van a 
faltar en un futuro las ayudas comunitarias: es un fenómeno profundo y generalizado en Europa que en ETEA hemos denominado el tránsito del paradigma "productivista» al «ruralista». Su legitimación es incuestionable y su defensa ante los ciudadanos / contribuyentes comunitarios muy fácil, desde luego mucho más fácil que la defensa de las subvenciones agrarias actuales...

Pero, para ello, deben cambiar de raíz las actitudes básicas de los agentes económicos, incluidas las fuerzas sociales, empresariales, sindicales, políticas. Toda la carne debe ser puesta en el asador de la creatividad, la innovación, el ahorro, la inversión y la asunción de riesgos; la capacidad de competir, de producir para el mercado, de exportar, de captar valor añadido a los productos locales.

¿Esas actitudes están siendo fortalecidas con batallas como la del aceite de oliva? Estamos persuadidos de que no; más aún, estas batallas debilitan el tejido empresarial y las iniciativas tendentes a la diversificación productiva, concentrando la atención de los potenciales creadores de riqueza en actividades escasamente generadoras de empleo.

Más grave nos parece la escasa capacidad de generación de empleo sobre todo de los grandes productores y de las burguesias olivareras ricas del sur, que no han sido capaces, ni la sociedad les ha presionado en ese sentido, de utilizar las cuantiosas rentas de situación que representan las ayudas comunitarias al aceite para producir cambios estructurales en las zonas olivareras. Este es un tema de enorme interés pendiente de investigar: ¿a qué destinan las subvenciones sobre todo sus principales beneficiarios?

La solución del problema del desempleo en las comarcas andaluzas de monocultivo olivarero no vendrá nunca vía subvenciones. Sólo en la medida en que los agentes económicos, sociales y políticos acometan un enérgico proceso de reactivación económica y diversificación productiva, existirá para estas vastas áreas una esperanza de futuro. Si no, aun en la hipótesis de que se gane esta batalla, se habrá perdido la guerra. Una vez más habremos conseguido "pan para hoy y hambre para mañana». Nunca mejor dicho...

Resumiendo para terminar, estamos ante un conflicto complejo. En él es tan difícil como necesario tener claro cuáles son los verdaderos «intereses 
generales», que no siempre coinciden con los defendidos por los movimientos corporativos más ruidosos. Las dificultades aumentan porque aparecen ciertos rasgos característicos del fundamentalismo en este panorama ya complicado: un enemigo común demonizado, fácilmente identificable; un colectivo supuestamente «homogéneo» que se considera agredido; una lucha aparentemente «unánime». Pero nosotros pensamos -y creemos haber puesto de manifiesto- que no está tan claro quién es realmente el enemigo, ni que todos los que se consideran perjudicados lo sean y de la misma forma, ni que todos los que luchan en esta batalla lo hagan por razones similares y por «causas justas».

Titulábamos este articulo editorial «La batalla del aceite». Como en todas las batallas, puede que también en ésta haya víctimas inocentes. Realmente son ésas las que nos interesan. Y no son otras que el mundo rural propiamente dicho en general y, más en particular, la población rural menos protegida y frecuentemente desempleada. 